\title{
ESTABILIDADE DE BIOSSURFACTANTE BACTERIANO DO TIPO LIPOPEPTÍDEO FRENTE ÀS VARIAÇÕES DE TEMPERATURA, pH E CONCENTRAÇÕES SALINAS
}

\author{
B. N. SANTOS ${ }^{1}$, J. A. M. $\operatorname{LEMOS}^{1}$, S. LEMOS $^{2}$, A. PARENTE ${ }^{1}$, Í. W. L. DE
} FRANÇA $^{1}$, V. M. M. MELO ${ }^{3}$, H. BATISTA ${ }^{1}$ e L. R. B. GONÇALVES ${ }^{1}$

\author{
${ }^{1}$ Universidade Federal do Ceará,Departamento de Engenharia Química \\ ${ }^{2}$ Universidade Federal do Ceará,Departamento de Engenharia de Alimentos \\ ${ }^{3}$ Universidade Federal do Ceará,Departamento de Biologia \\ Email para contato: lrg@ufc.br
}

\begin{abstract}
RESUMO - Recentemente, têm-se dado grande ênfase aos impactos ambientais causados pelos surfactantes químicos. Os compostos de origem microbiana que exibem propriedades surfactantes, isto é, diminuem a tensão superficial e possuem alta capacidade emulsificante, são denominados biossurfactantes e consistem em metabólicos microbianos. A aplicabilidade de biossurfactantes em biorremediação e diversos setores industriais dependem da estabilidade de suas propriedades funcionais. Os objetivos deste estudo foram avaliar a estabilidade das ações tensoativa e emulsificante do biossurfactante produzido pela cepa ICA56, frente às variações ambientais de $\mathrm{pH}$, temperatura e força iônica. As propriedades emulsificante e tensoativa do bioproduto produzido no cultivo da cepa ICA56 mostraram-se estáveis e eficientes frente às variações de $\mathrm{pH}$, temperatura e força iônica, mostrando sua aplicabilidade. Dentre as condições avaliadas, o $\mathrm{pH}$ mostrou-se o que mais apresentou efeito sobre as propriedades do biossurfactante. Este bioproduto foi ainda efetivo como tensoativo e emulsificante, mas com eficiência reduzida para $\mathrm{pH}$ inferior a 4.
\end{abstract}

\section{INTRODUÇÃO}

Biossurfactantes constituem uma série de espécies químicas com propriedades tensoativas similares aos surfactantes químicos. São produzidos extracelularmente ou como parte da membrana celular de bactérias, leveduras e fungos e apresentam algumas vantagens em relação aos surfactantes químicos: baixa toxidade, aceitabilidade ambiental, biodegradabilidade no solo e na água, possibilidade de produção por fontes renováveis, além de tolerância à condições extremas de temperatura, $\mathrm{pH}$ e força iônica, e serem biodegradáveis no solo e na água. Os biossurfactantes são mais eficientes do que os surfactantes sintéticos, pois produzem menor tensão superficial em menores concentrações de tensoativo (AL-BHARY et al. 2013; REIS et al. 2013).

O potencial de aplicação dos biossurfactantes é baseado em suas propriedades funcionais, que incluem emulsificação, separação, solubilização, inibição de corrosão, agente quelante, redução de viscosidade de líquidos e redução da tensão superficial. 
Estas propriedades funcionais de cada biossurfactante podem variar dependendo do meio de cultivo e micro-organismo utilizados, bem como das condições operacionais, tais como pH, temperatura, agitação e aeração do sistema reacional (REIS et al. 2013). A aplicabilidade de um biossurfactante depende da sua estabilida de propriedades funcionais frente variações de condições ambientais. Segundo Vaz et al. (2012), os biossurfactantes apresentam propriedades que os caracterizam como potenciais insumos em diversos setores e processos industriais. Estes processos estão normalmente associados a condições extremas (tais como $\mathrm{pH}$, temperatura ou salinidade), sendo então necessária uma avaliação da estabilidade desses biossurfactantes frente à essas condições. Alguns campos de aplicação dos biossurfactantes dependem estritamente que suas propriedades funcionais permaneçam praticamente inalteradas frente às variações ambientais em que está sujeito, tais como temperatura, $\mathrm{pH}$ e concentração salina.

Dentro deste panorama, o presente trabalho tem como objetivo avaliar as propriedades funcionais, tais como emulsificante e tensoativa, do biossurfactante produzido pela cepa ICA56 frente a variações de pH, concentração salina e temperatura.

\section{MATERIAIS E MÉTODOS}

\subsection{Micro-organismo e meio de estoque}

A cepa ICA56 foi previamente isolada de manguezal no município de Icapuí (Barra Grande) no estado do Ceará. Este micro-organismo foi apresentado como potencial produtor de biossurfactante por Lima (2013), por intermédio da identificação do gene $s f p$, responsável pela produção de surfactina, através de técnica de $P C R$ (Reação em Cadeia da Polimerase). Esta linhagem pertence à coleção de bactérias do Laboratório de Ecologia Microbiana e Biotecnologia (LEMBIOTECH) do Departamento de Biologia da Universidade Federal do Ceará e foi gentilmente cedida para a realização do presente estudo. A linhagem foi mantida em meio APGE (ágar/peptona/glicose/extrato de levedura) e repicada a cada 30 dias.

\subsection{Produção e obtenção do biossurfactante bruto}

A cepa ICA56 foi cultivada em meio mineral (BARRETO, 2011) contendo glicose $\left(10,0\right.$ g. $\left.\mathrm{L}^{-1}\right)$ como fonte de carbono e sulfato de amônio $\left(1,0\right.$ g. $\left.\mathrm{L}^{-1}\right)$ como fonte de nitrogênio. Para a realização dos ensaios, adicionou-se (10\% de inóculo) ao meio de cultivo, para um volume final de fermentação de $100 \mathrm{~mL}$. O ensaio foi realizado em agitador orbital a $30^{\circ} \mathrm{C}$ e $180 \mathrm{rpm}$, durante 48 horas. Após o período de cultivo, a biomassa foi removida por centrifugação a $10000 \mathrm{~g}$, a $4^{\circ} \mathrm{C}$ por 15 minutos e $\mathrm{o}$ sobrenadante foi acidificado para $\mathrm{pH} 2,0 \mathrm{com} \mathrm{HCl} 3 \mathrm{M}$. A solução resultante permaneceu em repouso por aproximadamente 24 horas $\left(4^{\circ} \mathrm{C}\right)$ para que ocorresse a precipitação do biossurfactante. O extrato rico em biossurfactante foi centrifugado (10000 g, a $4^{\circ} \mathrm{C}$ por 15 minutos) e o precipitado obtido foi conduzido para estufa de secagem $\left(50{ }^{\circ} \mathrm{C}\right.$, por 24 horas), fornecendo assim o biossurfactante bruto (PERREIRA et al. 2013).

\subsection{Caracterização das propriedades funcionais do biossurfactante produzido pela cepa ICA56 em meio mineral}

Tensão superficial e interfacial: Utilizou-se Tensiômetro Krüss, modelo K6, de acordo com o método descrito por Costa et al. (2006). 
Índice de emulsificação: $\mathrm{O}$ índice de emulsificação foi determinado de acordo com a metodologia proposta por Wei et al. (2005). As fontes hidrofóbicas utilizadas na formulação da emulsão foram óleo de soja e óleo de motor SAE 15W-40. Analisou-se a estabilidade da emulsão formada em período de 24 horas.

\subsection{Estabilidade frente variações de pH, temperatura e concentrações salinas}

A avaliação da estabilidade das propriedades tensoativas e emulsificantes do biossurfactante bruto foi realizada de acordo com a metodologia proposta por Aparna et al. (2012). Foram preparadas soluções do biossurfactante bruto $\left(0,35 \mathrm{mg} \cdot \mathrm{mL}^{-1}\right)$ e então expostas às variadas de condições de $\mathrm{pH}(2,4,6,8,10$ e 12$)$, temperatura $(4,25,50,75$, 100 e $121^{\circ} \mathrm{C}$, por 30 minutos de exposição em mufla) e concentrações salinas $(0 ; 2,5 ; 5$, 10,15 e $20 \% \mathrm{~m} / \mathrm{v}$ de $\mathrm{NaCl}$ ). Posteriormente foram avaliados o índice de emulsificação $\left(E_{24}\right)$, utilizando óleo de motor e óleo de soja, bem como as tensões superficiais.

\section{RESULTADOS E DISCUSSÃO}

A Figura 17 apresenta o efeito da variação do $\mathrm{pH}$ nas propriedades tensoativas e emulsificantes do biossurfactante produzido pela cepa ICA56.

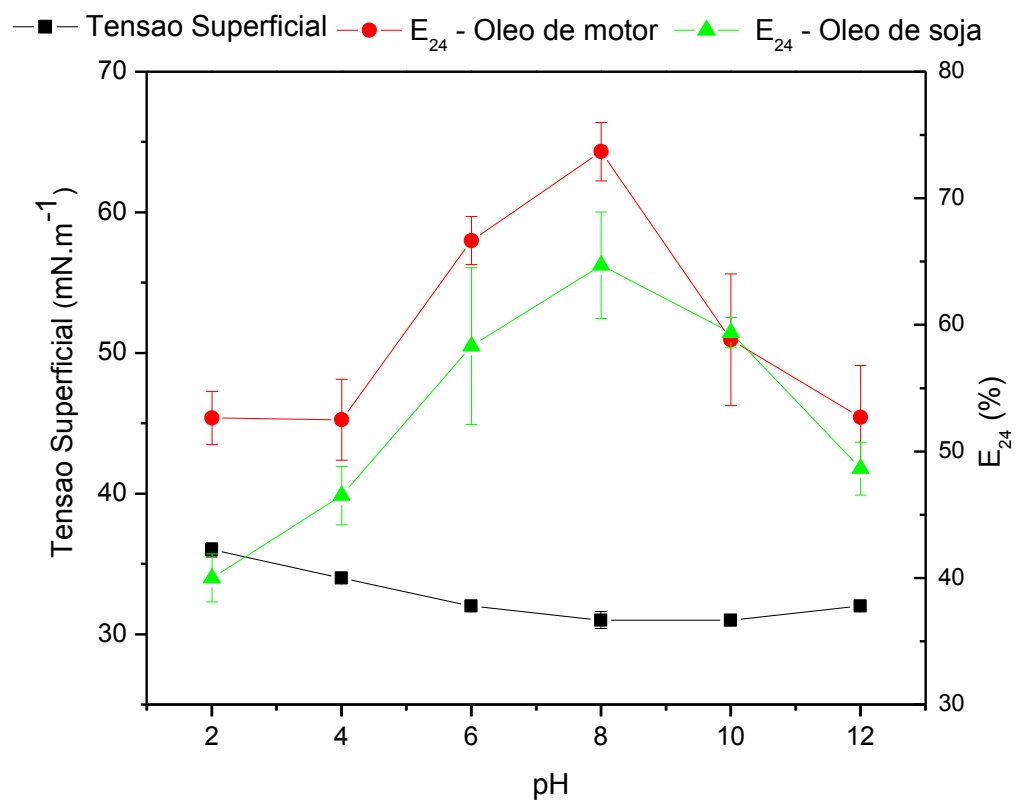

Figura 1 - Efeito da variação do $\mathrm{pH}$ no Índice de Emulsificação( $\left.\mathrm{E}_{24}\right)$ na emulsão formada em óleo de motor $(\bullet)$ e óleo de soja $(\boldsymbol{\Delta})$ e na atividade superficial ( $\boldsymbol{( \boldsymbol { a } )}$ no biossurfactante produzido pelo cultivo da cepa ICA56 em meio mineral.

Observa-se na Figura 1 que o biossurfactante produzido apresentou menor valores de tensão superficial e maiores resultados de índice de emulsificação na faixa de $\mathrm{pH}$ de 6,0 a 10,0. No pH 8,0 o biossurfactante foi capaz de reduzir a tensão superficial da água de 72 para $31 \mathrm{mN} \cdot \mathrm{m}^{-1}$, representando um redução de aproximadamente $57 \%$. Este resultado nesta faixa de $\mathrm{pH}$ era esperado, tendo em vista as características do biossurfactante produzido, pois em $\mathrm{pH}$ mais próximos à neutralidade $(\mathrm{pH} 7,0)$, a surfactina permanece solubilizada em solução, mantendo suas propriedades tensoativas e emulsificantes. Apesar de que na faixa mais próxima da neutralidade, em todos os valores de $\mathrm{pH}$ estudados, a tensão superficial, permaneceu inferior a $37 \mathrm{mN} . \mathrm{m}^{-1}$. 
Quando se avaliou o índice de emulsificação frente a óleo de motor, observou-se que em todas as faixas de $\mathrm{pH}$ analisados, os valores de $\mathrm{E}_{24}$ foram superiores a $50 \%$, indicando a eficiência do tensoativo produzido. Este resultado de estabilidade na emulsão formada também foi observado quando se utilizou óleo de soja, exceto para os $\mathrm{pH}$ de 2,0 e 4,0 .

Valores consideravelmente ácidos do meio causam a precipitação da surfactina, causando possível perda desse produto. Devido à presença dos ácidos glutâmico e aspártico (aminoácidos) na estrutura da surfactina, o contato com $\mathrm{HCl}$, ou outro ácido, causa a protonação da cadeia lateral destes aminoácidos, tornando a surfactina insolúvel em meio aquoso (GUDINA et al. 2010). Valores acentuadamente ácidos de pH podem causar alterações nas forças eletrostáticas envolvidas na formaçõe de emulsões, o que pode acarretar a coalesência (separação) das fases envolvidas.

A variação do $\mathrm{pH}$ no meio pode também afetar a estrutura e o tamanho das micelas formadas entre o biossurfactante e o sistema água-óleo. Knoblich et al. (1995) observaram que a variação do $\mathrm{pH}$ alterou o tamanho e o formato das micelas produzidas pela surfactina. Nos valores de $\mathrm{pH}$ mais próximos a neutralidade, a micela apresenta uma estrutura globular e e elipsoidal. Já em condições mais alcalinas, a estrutura passava para um formato globular e clindrico e com tamanho maior do que em $\mathrm{pH}$ mais ácidos ou neutros. Um tamanho de micela maior pode agregar uma maior quatidade material de um sistema água-oleo.

Os resultados de estabilidade do biossurfactante, frente a variações de $\mathrm{pH}$, foram semelhantes aos reportados por Al-Bahry et al. (2013) e Al-Wahaibi et al. (2013).

A fim de se analisar o efeito da temperatura nas propriedades tensoativas e emulsificantes do biossurfactante em estudo, alíquotas de solução do biossurfactante bruto foram expostos à diferentes temperaturas $\left(4,25,50,75,100\right.$ e $\left.121{ }^{\circ} \mathrm{C}\right)$ por 30 minutos. A Figura 2 apresenta o efeito da variação da temperatura no índice de emulsificação $\left(E_{24}\right)$ na emulsão formada em óleo de motor e óleo de soja, e na tensão superficial de solução rica em biossurfactante bruto.

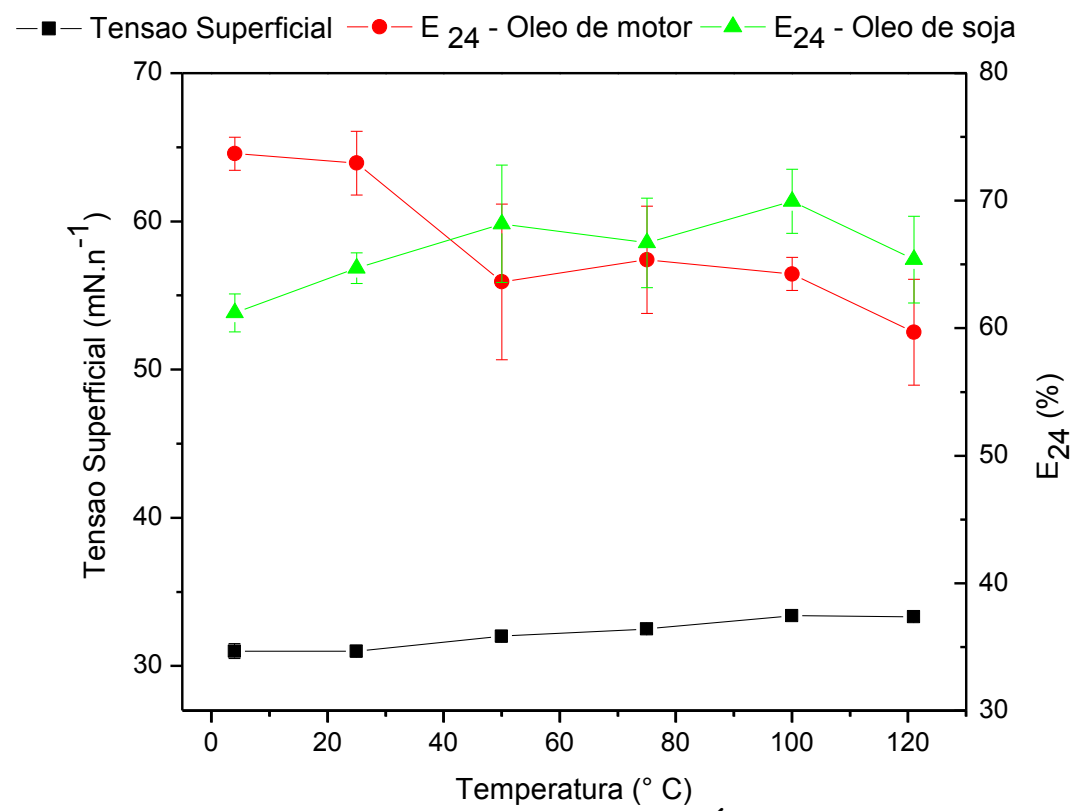

Figura 2 - Efeito da variação da temperatura no Índice de Emulsificação( $\left.E_{24}\right)$ na emulsão formada em óleo de motor $(\bullet)$ e óleo de soja $(\boldsymbol{\Delta})$ e na atividade superficial ( $\bullet$ ) no biossurfactante produzido pelo cultivo da cepa ICA56 em meio mineral. 
A Figura 2 mostra que apesar do tratamento térmico na solução rica em biossurfactante bruto, tanto as propriedades tensoativas como emulsificantes não apresentaram mudanças significativas nas temperaturas de 4 a $120{ }^{\circ} \mathrm{C}$.

A tensão superficial da solução de biossurfactante permaneceu na faixa entre $31 \mathrm{e}$ $33 \mathrm{mN} . \mathrm{m}^{-1}$, mostrando a estabilidade da atividade superficial do tensoativo produzido frente as variações de temperaturas analisadas. As emulsões analisadas em óleo de motor e óleo de soja também apresentaram estabilidade apresentando valores de índice de emulsificação entre 60 e $75 \%$ para a faixa de temperatura analisada.

Diversos estudos confirmam a estabilidade das propriedades dos biossurfactantes quando submetidos a condições extremas de temperatura. Joshi et al. (2008) reportaram que os biossurfactantes produzido por 4 cepas de Bacillus sp. permaneceram com suas propriedades estáveis, quando submetidos à $80{ }^{\circ} \mathrm{C}$ durante nove dias. Vaz et al. (2012) também observaram a estabilidade do biossurfactante produzido por cepas de Bacillus $s p$., isolada de ambiente contaminado com petróleo, quando submetidos a condições extremas de temperatura.

Segundo Khopade et al. (2012), a estabilidade térmica de um biossurfactante é um resultado interessante no que se relaciona a aplicabilidade de um produto. Em alguns setores industriais a estabilidade térmica é um fator crucial, tais como nas indústrias alimentícia, cosmética e farmacêutica, em que há necessidade de estilização de certos produtos por tratamento térmico.

$\mathrm{O}$ efeito da adição de $\mathrm{NaCl}$ (a de 0 a $20 \% \mathrm{~m} / \mathrm{v}$ ) à uma solução rica em biossurfactante também foi analisado, em termos de tensão superficial e índice de emulsificação. A Figura 3 apresenta os resultados deste estudo.

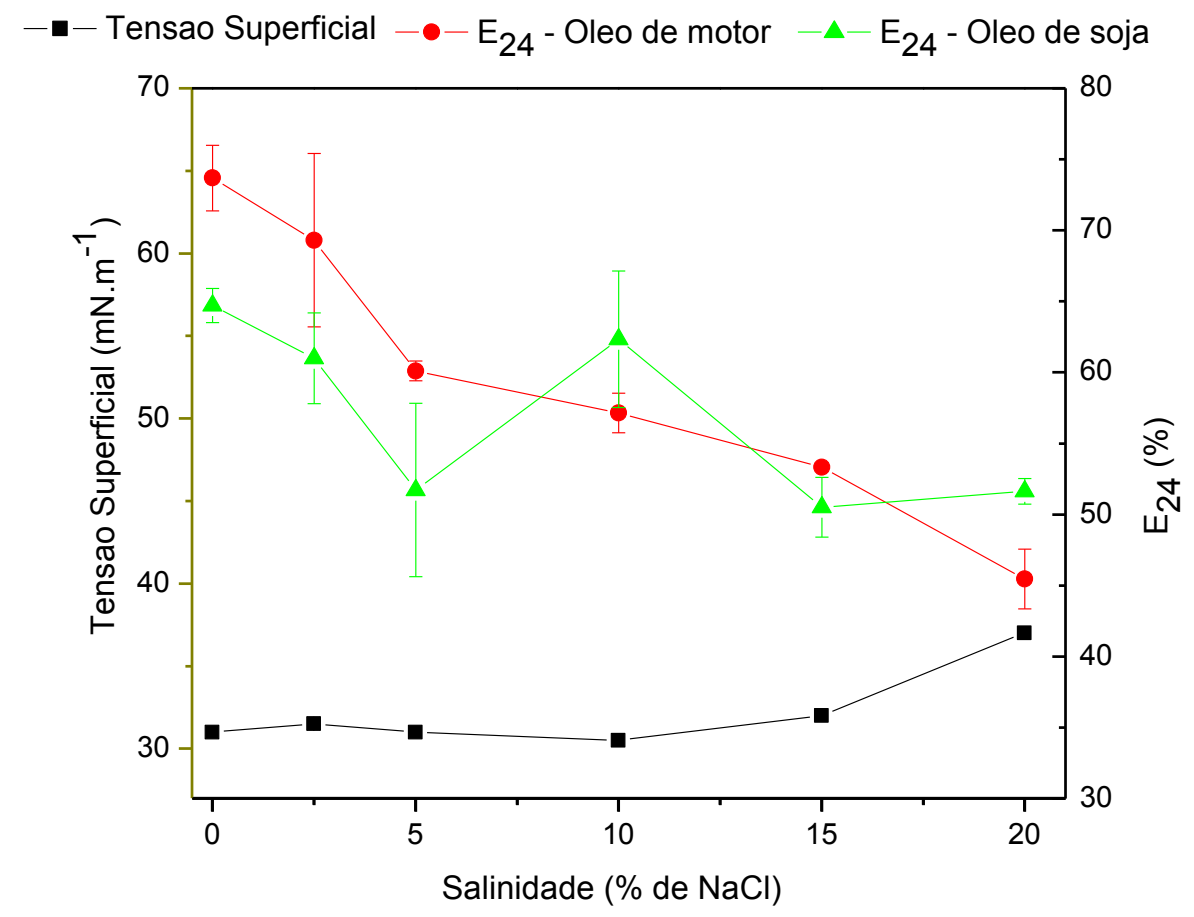

Figura 3 - Efeito da variação da força iônica no Índice de Emulsificação(E $\left.E_{24}\right)$ na emulsão formada em óleo de motor $(\bullet)$ e óleo de soja $(\boldsymbol{\Delta})$ e na atividade superficial ( $\square$ ) do biossurfactante produzido pelo cultivo da cepa ICA56 em meio mineral.

Observou-se que os índices de emulsificação apresentaram um decréscimo à medida que a concentração salina foi aumentada. Entretanto a maioria dos valores de $\mathrm{E}_{24}$ permaneceu superior a $50 \%$, indicando a eficiência do biossurfactante. A emulsão 
formada em óleo de soja apresentou maior estabilidade, frente à variação de força iônica, do que a formada em óleo de motor. Na maior concentração analisada $(20 \%$ $\mathrm{m} / \mathrm{v}$ ) a emulsão formada em óleo de motor apresentou índice de emulsificação de aproximadamente $45 \%$, apresentando indícios que para esta concentração salina, o biossurfactante analisado não apresente a mesma eficiência como emulsificante, do que nas outras analisadas.

Já a tensão superficial não apresentou variação tão significativa, permanecendo estável em uma faixa entre 31 e $32 \mathrm{mN} . \mathrm{m}^{-1}$, com exceção para a concentração de $20 \%$ de $\mathrm{NaCl}$, cuja solução apresentou tensão de $37 \mathrm{mN} . \mathrm{m}^{-1}$. Este resultado reforça a possibilidade que para esta concentração salina, a eficiência do biossurfactante seja levemente reduzida. Apesar do suave aumento na tensão superficial na concentração de $\mathrm{NaCl}$ mais elevada, o biossurfactante produzido ainda foi capaz de reduzir cerca de $48 \%$ na tensão superficial. Até $10 \%$ de salinidade, foi observada variação insignificante na nas propriedades tensoativas do biossurfactante produzido. Os biossurfactantes suportam concentrações de $10 \%$ de $\mathrm{NaCl}$ enquanto que concentrações salina de 2 a $3 \%$ são suficientes para inativar surfactantes convencionais (NITSCHKE \& PASTORE, 2002).

Knoblich et al. (1995) observaram que a adição de sal a solução de surfactina provoca uma mudança no tamanho da micela formada. Elevadas concentrações salinas podem diminuir consideravelmente o tamanho da micela e afetar as propriedade funcionais deste biossurfactante.

Shaw (1970) propõe que os sais iônicos formam interações íon-dipolo com a água. Estas interações são mais fortes do que as formadas entre o sal e a fase gasosa (ar), e estas moléculas evitam a interface ar/sistema aquoso, gerando um aumento na tensão superficial de uma solução.

Segundo Mohamed et al. (2003), com o aumento da concentração salina, também é observado um aumento na energia livre do sistema. Então as emulsões formadas não são termodinamicamente estáveis, proporcionando um aumento na taxa de coalescência das gostas e posterior separação de fases.

Al-Bahryet al.(2013) e Al-Wahaibiet al.(2013) reportaram que o biossurfactante produzido pro cepas de Bacillus sp. apresentou estabilidade tensoativa até $5 \%$ de salinidade. Felix (2012) também observou tensão de $37 \mathrm{mN} \cdot \mathrm{m}^{-1}$ pra solução rica em surfactina com $20 \%$ de $\mathrm{NaCl}(\mathrm{m} / \mathrm{v})$ e que o biossurfactante permaneceu estável até $10 \%$ de salinidade, ao avaliar a produção de surfactina pelo cultivo da cepa de Bacillus subtilis LAMI005 em suco de caju clarificado.

Khopade et al. (2012) propõem que biossurfactantes que suportem até $10 \%$ de salinidade apresentam viabilidade à utilização na biorremediação de ambientes marinhos.

\section{CONCLUSÃO}

As propriedades emulsificante e tensoativas do bioproduto formado no cultivo da cepa ICA56 mostraram-se estáveis e eficientes frente às variações de $\mathrm{pH}$, temperatura e concentração salina, mostrando sua aplicabilidade, já que diversas de suas aplicações dependem destas características. Dentre as condições avaliadas, o pH mostrou-se o que mais apresentou algum efeito sobre as propriedades do biossurfactante, mas ainda assim este bioproduto foi efetivo como tensoativo e emulsificante, mas com eficiência reduzida em valores ácidos de $\mathrm{pH}$ (inferiores a 4). Esta estabilidade de suas propriedades funcionais mostra indícios do potencial de aplicabilidade do biossurfactante produzido pela cepa ICA56. 


\section{REFERÊNCIAS BIBLIOGRÁFICAS}

AL-BAHRY, N.; AL-WAHAIBI, Y. M.; ELSHAFIE , A. E. Biosurfactant production by Bacillus subtilis B20 using date molasses and its possible application in enhanced oil recovery, International Biodeterioration Biodegradation, vol.81, p.141-146, 2013.

AL-WAHAIBI ,Y.; SANKET, J.; AL-BAHRY, S.; ELSHAFIE, A.; AL-BEMANI, A.; SHIBULAL B., Biosurfactant production by Bacillus subtilis B30 and its application in enhancing oil recovery, Colloids and Surfaces B: Biointerfaces, v. 114, p. 324-333, 2013.

APARNA, A; SRINIKETHAN, G.; SMITHA, H. Production and characterization of biosurfactant produced by a novel Pseudomonas sp. 2B, Colloids and Surfaces B, vol. 95, p. 23-29, 2012.

BARRETO, R. V. G., Prospecção de micro-organismos e genes envolvidos com a produção de biossurfactantes em solos de manguezais, 2011. Tese (Doutorado em Doutorado em Biotecnologia) - Rede Nordeste de Biotecnologia (RENORBIO) Universidade Federal do Ceará, 2011.

COSTA, S. G. V. A. O., NITSCHKE, M., HADDAD, R., EBERLIN, M. N., CONTIERO, J., Production of Pseudomonas aeruginosa LB1 rhamnolipids following growth on brazilian native oils. Proc. Biochem., v. 41, p. 483 - 488, 2006.

FELIX, A. K. Caracterização e estudo da aplicabilidade do biossurfactante produzido por Bacillus subtilis LAMI005 a partir de suco de caju. 2012. Dissertação (Mestrado em Engenharia Química) Departamento de Engenharia Química, Universidade Federal do Ceará (UFC) Fortaleza - Ceará, 2012.

GUDINA, E. J.; TEIXEIRA J, A.; RODRIGUES L. R.; Isolation and functional characterization of a biosurfactant produced by Lactobacillus paracasei, Colloids Surf B Biointerfaces, v. 76 (1) p. 298-304, 2010.

JOSHI, S.; BHARUCHA, C.; JHA, S.; YADAV, S.; NERURKAR, A;.A. J. DESAI. Biosurfactant production using molasses and whey under thermophilic conditions, Bioresource Technology, vol. 99, p. 195-199, 2008.

KHOPADE, A.; REN, B.; LIU, X.; MAHADIK, K.; ZHANG, L.; KOKARE, C. Production and characterization of biosurfactant from marine Streptomyces species B3, Journal of Colloid and Interface Science, v. 367, p. 311-318, 2012.

KNOBLICH, A.; MATSUMOTO, M.; ISHIGURO, R.; MURATA, K.; FUJIYOSHI, Y.; ISHIGAMI, Y.; OSMAN, M., Electron Cryo-Microscopic Studies on Micellar Shape and Size of Surfactin, an Anionic Lipopeptide. Colloids Surf B Biointerfaces, v. 5 (1-2) p. 43-48, 1995.

LIMA, L. B., Frequência de bactérias produtoras de biossurfactantes lipopeptídeos em sedimentos de manguezais do Ceará, 2002. Dissertação (Mestrado em Ciências Marinhas Tropicais) - Intituto Ciências do Mar, Universidade Federal do Ceará, Fortaleza, 2002. 
MOHAMED, A. O.; GAMAL, M.; ZEKRI, A. Y. Effect of salinity and temperature on water cut determination in oil reservoirs, Journal of Petroleum Science and Engineering, v. 40, .p 177-188, 2003.

NITSCHKE, M.; PASTORE, G. M. Biossurfactantes: Propriedades e aplicações. Quím. Nova, v. 25, p. 772-776, 2002.

PEREIRA, J. F. B.; GUDIÑA, E. J.; COSTA, R.; VITORINO, R.; TEIXEIRA, J. A.; COUTINHO, J. A. P.; RODRIGUES, L. R.; Optimization and characterization of biosurfactant production by Bacillus subtilis isolates towards microbial enhanced oil recovery applications, Fuel, v. 111, p. 259-268, 2013.

REIS, R. S.; PACHECO, G. J.; PEREIRA, A. G.; FREIRE, D. M. G. Biosurfactants: Production and Applications, Biodegradation - Life of Science, Dr. Rolando Chamy (Ed.), InTech, 2013, v. 01, p. 1-370, 2013.

SHAW, D. J. Introduction to colloids and surface chemistry. Editora Edgar Blucher Ltda, p. 181, 1970.

VAZ, D. A.; GUDIÑA, E. J.; ALAMEDA, E . J.; TEIXEIRA, J. A.; RODRIGUES, L. R. Performance of a biosurfactant produced by a Bacillus subtilis strain isolated from crude oil samples as compared to commercial chemical surfactants, Colloids and Surfaces B: Biointerfaces, v. 89, p. 167-174, 2012.

WEI, Y.; CHOU, C.; CHANG, J. Rhamnolipid production by indigenous Pseudomonas aeruginosa originating from petrochemical wastewater. Biochemical Engineering Journal, v. 27, p. 146-154, 2005. 